Research CommentaRies: Food Systems Research Priorities over the NeXt 5 Years

\title{
A regional economics-based research agenda for local food systems
}

\author{
Kathryn A. Boys, ${ }^{\mathrm{a}, *}$ Virginia Tech \\ David W. Hughes, ${ }^{\mathrm{b}}$ Clemson University
}

Submitted June 5, 2013 / Revised August 13, 2013 / Published online September 3, 2013

Citation: Boys, K. A., \& Hughes, D. W. (2013). A regional economics-based research agenda for local food systems. Journal of

Agriculture, Food Systems, and Community Development, 3(4), 145-150. http://dx.doi.org/10.5304/jafscd.2013.034.012

Copyright (C) 2013 by New Leaf Associates, Inc.

\begin{abstract}
The purported benefits of local food systems (LFSs) are extensive and diverse. While a growing general literature has considered various aspects of these systems, this set of issues has not been considered broadly from the perspective of regional economics - a field that is uniquely suited to assess local food systems and the policies that affect them. This commentary attempts to narrow this gap. Research topics are considered that would allow for improved examination of the extent to which LFS directly and indirectly engender local economic growth. Also incorporated are research ideas concerning how to determine the

a Assistant professor, Department of Agricultural and Applied Economics, Virginia Tech

b Professor, School of Agriculture, Forestry, and Environmental Sciences, Clemson University, Clemson, South Carolina 29634-0313 USA; dhughe3@,clemson.edu

* Corresponding author: Kathryn A. Boys, 322 Hutcheson Hall (0401), Virginia Tech, Blacksburg, Virginia 24061 USA; +1-540-231-0770; kboys@,vt.edu
\end{abstract}

distribution of benefits (socially, across income class, and geographically). In this regard, suggestions are also made concerning how to remove some of the limitations found in current analytical approaches.

\section{Keywords}

impact analysis, social capital, quality of life, regional branding

\section{Introduction}

The purported benefits of local food systems are extensive and diverse. While a growing literature has considered various aspects of these systems, this issue has not been broadly considered from the perspective of regional economics. As this discipline evaluates the influence of location and distance on economic activity (Edwards, 2007), it is uniquely suited to assess local food systems (LFSs) and the policies that affect them.

This paper centers on the effect of LFSs on local and regional economies. Through a set of stylized statements, the mechanisms through which 
these systems could engender local economic growth, and related research gaps, are considered.

\section{LFSs Are a Source of Economic Growth}

The potential economic development benefits available through LFSs are diverse and seemingly large. Small- and medium-sized agricultural producers are thought to benefit by an expanded demand for their products. In turn, those who supply production inputs (including labor), and other industries that support and complement the food system, also benefit from an increase in demand for their products and services. In distilling these benefits, two mechanisms through which these benefits may be generated and assessed emerge. The first is the concept of interfirm networks that are formed through agglomeration, firm clustering, and ultimately regional competitiveness. The second means of benefit generation is through backwards and forwards supply-chain linkages.

Agglomeration economies are generated when firms gain a productivity advantage from being physically proximate to one another. Many of the positive externalities of agglomeration are derived from the transfer of information and exchange of ideas between firms that are agglomerated as compared to those that are not geographically close. Physical proximity allows for face-to-face interactions (both formal and informal) between staff of firms in the same or related industries, as well as other firms in the geographic area. Relationships are established that facilitate (more) open information and knowledge exchanges on matters such as technical advice, information about input suppliers, new regulations, market opportunities, job opportunities, ideas, and firm and industry rumors (e.g., Enright, 1995; Cross, Borgatti, \& Park, 2001).

Clusters, a related concept, are "geographic concentrations of interconnected companies, specialized suppliers, service providers, firms in related industries, and associated institutions in a particular field, that compete but also cooperate in producing similar products" (Porter, 2000, p. 15). To the extent that clustering occurs and generates positive spillover effects, these can stimulate and strengthen LFSs.
Firms are known to particularly benefit from agglomeration in high population areas where concentration allows for increasing returns due to improved growth and productivity. It is uncertain, however, to what extent they may exist in more rural LFSs. Are concentrations of customers sufficient to induce these positive externalities? If clustering does occur, to what extent is it driven by "blind" market forces where food producers merely co-locate without any real cooperation among themselves or with other entities? Or, are the benefits generated when plied by intentional action, such as when involved parties work together to achieve policies, goals, and/or are aware of the importance of spatially based linkages?

The tendency of LFSs to cluster has received little research attention and has not undergone rigorous statistical analysis. Ilbery, Watts, Simpson, Gilg and Little (2006) explored the extent to which food producers, processors, and retailers were involved in the production of local foods in the Southwest and Midlands regions of England. Using a geographical analysis, they determined that LFSs tended to cluster in certain areas. Proximity to higher-income urbanized areas, certain tourist attractions, small landholdings, and certain types of agriculture, such as vegetable production, were positively correlated with LFS geographic concentration.

A related matter is whether the presence of local food firms or facilitating organizations enhance the probability of future LFS development. Does the development of one successful marketing channel (e.g., farmers' markets) tend to foster the development of other channels (e.g., CSAs), or do alternative channels develop independently? Does the existence of a farmers' market lead to additional farmers' markets because of knowledge spillovers or other factors? And if so, are the supply and demand of LFS products sufficient to allow all to thrive? The limited early research on this latter point is not encouraging. Lohr and Diamond (2011), and antidotal information (Zezima, 2011) indicate that new farmers' markets may cannibalize older markets through competition for customers and/or vendors (i.e., a 
form of "beggar thy neighbor"; discussed in statement 5).

Answering these questions through rigorous statistical analysis and case studies will yield further insight into the relationships between LFS stakeholders and their relative roles. From there, identifying growth trajectories and constraints for a specific LFS, and assessing the overall economic impact of LFSs in a given region are a natural next step.

\section{The Economic Impact of LFSs Can Be Quantified and Is Substantial}

Regional or local input-output models have been used to estimate the economic impact of LFS through specific marketing channels (e.g., farmers' markets (Hughes, Brown, Miller \& McConnell, 2008); direct to institutional foodservice establishments (Thilmany, Gunter, \& Sullins, 2011) or production potentials (Swenson, 2011)). In general, such models are in need of improvement to better reflect the constraints and impacts of LFSs.

Defining the System: LFSs have been generally found to have a limited economic impact (Gale, 1997; Otto \& Varner, 2005). Hughes et al. (2008), for example, estimated that farmers' markets in West Virginia offered a net impact of 71 jobs. While the examined geographic area does shape these findings, results are also largely driven by the often-narrow range of activities considered as part of an LFS. Discussion in much empirical literature focuses on only small- and medium-scale farm production, and the direct-to-consumer marketing channel. For analyses to potentially generate the significant economic impact proffered by its proponents, the empirical concept of LFSs must be expanded to encompass a broader range of marketing channels and activities including distribution and logistic services, and food processing.

Data and Model Design: To date, most analyses have made use of "step-down" regional models such as IMPLAN or RIMS. Key parameters in these models, however, are based on national averages for an industry, which are then adjusted to reflect regional supply and demand relationships. For example, national estimates may be generated of the value of chemical fertilizer per dollar of revenue for tomatoes. In analyzing a region where chemical fertilizer is produced, the national inputoutput coefficient may be adjusted downward to reflect a lower local cost.

Importantly as well, national coefficients are derived using data that reflects production inputs and outputs across all farm sizes and types. But local food producers tend to differ from these national norms in several important ways. Beyond generally being smaller, these farms have a relative preferences for organic or other sustainable production practices, and often take on marketing functions completed by other types of firms in conventional systems (such as retailing). These features have cost implications. Further, due to the smaller volume of inputs purchased, and as these firms may have a preference for buying locally produced inputs, their per-unit input costs may be higher.

Improving these models requires improved data. If and how the mix of inputs differs for local food producers than for typical producers of a given product needs to be assessed. For example, the degree to which local and organic production inputs overlap, and the extent to which "local" farmers make and purchase inputs from local providers also requires further investigation. The greater the amount of inputs sourced locally, the greater the economic impact of an LFS. Surveys and case study research across the spectrum of LFS stakeholders (food hub participants, vendors in area farmers' markets, input suppliers, etc.) are required to generate more accurate regional economic model results.

Model Use and Results Interpretation: A holistic assessment of LFSs must also consider the costs of these systems. Purchase of LFS products may not increase food demand, but simply change where it is sourced. In such instances "local" spending reduces spending at retailers who sell nonlocal products. A more thorough accounting of the opportunity cost of resources and spending tied to LFSs is needed. The limited existing research that accounts for the opportunity cost for farmers' markets indicates that the reduction in economic impact is substantial (Hughes et al., 
2008; Hughes \& Isengildina-Massa, 2013). Further, the opportunity cost of inputs used in LFSs also should be considered. Resources used in LFS production could, in most cases, be repurposed; land and farmer expertise, for example, could be devoted alternatively to producing for export (Swenson, 2011). Research efforts are needed to determine how to quantify and include these types of opportunity costs in regional impact models.

Alternatively, the economic benefits may be underestimated. LFSs can attract "sticky" dollars by either implicitly attracting visitors who also patronize other local businesses or, through more general "buy local" initiatives, encourage dollars to be re-spent by locally owned and managed firms. The limited quantitative research done on this matter suggests that even small farmers' markets can lead to an increase in annual spending of US $\$ 19,900$ on nearby businesses (Market Umbrella, 2011).

The standard tools used for impact assessments, however, may not always be appropriate for analyzing LFSs. Should a food system become sufficiently large so as to influence regional labor and capital markets, price-flexible regional models, such as computable general equilibrium (CGE) models, may be needed to properly account for opportunity costs. Related to this are embeddedmodel assumptions concerning income distribution. Who accrues the benefits of LFS growth small producers who were of lower income, or individuals entering into agriculture production from higher income backgrounds? How are secondary or multiplier-based spending impacts of food systems distributed across income groups and retained in examined (including rural) geographic regions? Both properly constructed Social Accounting Matrix and CGE (Dervis, de Melo, \& Robinson, 1982) models could assess the extent to which different income classes benefit. Coreperiphery type regional models (Krugman, 1991) could provide information regarding the degree to which LFSs benefit more remote areas.

\section{LFSs Can Stimulate the Formation of Social Capital}

A growing body of literature indicates that social capital is an important element in LFS success
(Brasier et al., 2007; Korsching \& Allen, 2004). However, broader community implications of social capital development, including which groups benefit, are poorly understood. Do LFSs facilitate building connections between like-minded people? This is "bonding" social capital (Sabatini, 2008), and while it does build strong ties, it can also exclude those who are not of a similar mindset. Or are horizontal connections formed between heterogeneous groups of different backgrounds? In this case networks generate "bridging" social capital connecting sectors of society that otherwise would never come into contact (Sabatini, 2008). Alternatively, does "linking" social capital arise through linking individuals or the groups they belong to, with politically or financially powerful people or organizations? (Sabatini, 2008) The type(s) of social capital fostered by LFSs is key in determining who and how various social groups benefit. This is particularly important in valuing the benefits that accrue to traditionally disadvantaged groups such as minority farmers.

\section{LFSs Can Help Improve a Region's Quality of Life}

Florida (2002) argues that that the rise of the new economy has radically changed the ways that cities or regions establish and maintain their competitive advantage. Regional advantage is now based on quickly mobilizing the best people, resources, and capabilities to turn innovation into new business ideas and commercial products. As a result, attracting or generating, and retaining, the best talent is a way to engender regional economic growth. Quality of life factors such as regional amenities, lifestyle, and environmental quality are key ingredients of attraction and retention efforts.

Does a well-developed local food system make a place more attractive to the type of workers Florida argues are necessary for economic growth? If so, how important are LFSs to this strategy? Case studies of areas with strong LFSs and survey work are needed to explore these matters.

\section{LFSs Are Another Form of "Beggar Thy Neighbor"}

When one country or region imposes policy detrimental to others, retaliation may occur that ulti- 
mately may lead to everyone being worse off (Edwards, 2007). This phenomenon is known as "beggar they neighbor"; tariff-based trade wars are a classic example. As one region promotes its LFS, neighboring areas may do the same and the result may be a decline in regional exports for all. On an aggregate level, then, to what extent does an LFSbased import substitution policy lead to an inefficient allocation of resources?

To date, there has been no research on this issue as it applies to LFSs. Studies though have found value in interindustry advertising coordination (Alston, Freebairn, \& James, 2001), and interregional retail-firm recruitment in small or isolated rural areas (Thilmany, McKenney, Mushinski, \& Weiler, 2005). It stands to reason then that while within a region "local" branding may be effective, there may be benefit in coordinating across localities for regional branding to external consumers. This may be particularly true for value-added (processed) goods that are more easily sold beyond the local area. Numerical simulations or interregional trade models could be applied to examine these issues.

\section{LFS Products as the Basis of Regional Branding Strategies}

Those selling in LFSs frequently have an interest in expanding their markets - regardless of where their customers are located. Tapping into markets beyond the local region, however, usually requires processing of raw products and a strong external branding campaign. Under what situations do LFS have the potential to evolve into larger, more processing-oriented and/or export-oriented efforts? While case studies and specific feasibility analysis studies assess the potential for a particular LFS (or component thereof) to grow into a development engine, a more generalizable methodological approach is needed to evaluate this issue.

\section{Conclusion}

While it is a popular marketing trend, the extent to which LFSs offer economic, environmental, social, and health impacts of local food systems are unknown. Detracting from the potential impact of LFSs is the reality that conventional agricultural production and marketing systems are characterized by economies of scale. For most products in most regions, items produced "elsewhere," where economies of scale in production and industry cluster or agglomeration benefits may exist, will continue to hold cost advantages over LFSs. The extent to which customer willingness and ability to pay for locally grown foods trumps the cost advantage of nonlocal products will shape much of the future market size for these products.

Through enhancement of analytical techniques and examination of the highlighted issues, insights into how LFSs contribute and interact with economic development and growth will be deepened. The tools offered by regional economics may justify government investment, or motivate private investment, in this sector. Further, improvements to these analytical approaches should contribute to the development of better quality and more targeted public policies governing this food system. While research gaps in this field will not be easily filled, advancements will have the potential to generate substantial impacts.

\section{References}

Alston, J. M., Freebairn, J. W., \& James, J. S. (2001). Beggar-thy-neighbor advertising: Theory and application to generic commodity promotion programs. American Journal of Agricultural Economics, 83(4), 888-902. http://dx.doi.org/10.1111/0002$\underline{9092.00217}$

Brasier, K. J., Goetz, S., Smith, L. A., Ames, M., Green, J., Kelsey, T.,...Whitmer, W. (2007). Small farm clusters and pathways to rural community sustainability. Journal of the Community Development Society, 38(3), 8-22. http://dx.doi.org/10.1080/15575330709489826

Cross, R., Borgatti, S. P., \& Parker, A. (2001). Beyond answers: Dimensions of the advice network. Social Networks, 23(3), 215-235. http://dx.doi.org/10.1016/S0378-8733(01)00041-7

Dervis, K., de Melo, J., \& Robinson, S. (1982). General equilibrium models for development policy. Cambridge, UK: Cambridge University Press.

Edwards, M. (2007). Regional and urban economics and economic development. Boca Raton, Florida: Auerbach Publications. 
Enright, M. J. (1995). Organization and coordination in geographically and concentrated industries. In N. Lamoreaux \& D. Raff (Eds.), Coordination and Information: Historical Perspectives on the Organization of Enterprise (pp. 103-142). Chicago: Chicago University Press.

Florida, R. (2002). The rise of the creative class: And how it's transforming work, leisure and everyday life. New York: Basic Books.

Gale F. (1997). Direct farm marketing as a rural development tool. Rural Development Perspectives, 12(2), 19-25.

Hughes, D. W., Brown, C., Miller, S., \& McConnell, T. (2008). Evaluating the economic impact of farmers' markets using an opportunity cost framework. Journal of Agricultural and Applied Economics, 40(1), 253-265. http://purl.umn.edu/45523

Hughes, D. W., \& Isengildina-Massa, O. (2013, April). The impact of a buy local agriculture campaign on the South Carolina economy. Paper presented at the annual meeting of the Southern Regional Science Association, Washington, D.C.

Ilbery, B., Watts, D., Simpson, S., Gilg, A., \& Little, J. (2006). Mapping local foods: Evidence from two English regions. British Food Journal, 108(3), 213-225. http://dx.doi.org/10.1108/00070700610651034

Korsching, P. F., \& Allen, J. C. (2004). Local entrepreneurship: A development model based on community interaction field theory. Journal of the Community Development Society, 35(1), 25-43. http://dx.doi.org/10.1080/15575330409490120

Krugman, P. (1991). Increasing returns and economic geography. Journal of Political Economy, 99(3), 483499. http://dx.doi.org/10.1086/261763

Lohr, L., \& Diamond, A. (2011, July). Trade zones for farmers' markets: Spatial relationships. Paper presented at the CENET Track Session, Economic Contributions from a More Localized Food System, annual meetings of the American Agricultural and Applied Economics Association, Pittsburgh, Pennsylvania.

Market Umbrella. (2011). Sticky Economy Evaluation Device: Measuring the financial impact of a public market:
Baltimore Farmers Market (JFX) 2011. Retrieved from http://www.marketumbrella.org/ downloads/JFX BOPA-20111017.pdf

Otto, D. \& Varner, T. (2005). Consumers, vendors, and the economic importance of Iowa farmers' markets: An economic impact survey analysis. Ames, Iowa: Iowa State University, Leopold Center for Sustainable Agriculture. Retrieved from http://www.leopold.iastate.edu/

Porter, M. E. (2000). Location, competition, and economic development: Local clusters in a global economy. Economic Development Quarterly, 14(1), 15-34. http://dx.doi.org/10.1177/089124240001400105

Sabatini, F. (2008). Social capital and the quality of economic development. KYKLOS, 61(3), 466-499. http://dx.doi.org/10.1111/j.1467-6435.2008. 00413.x

Swenson, D. A. (2011, March). The regional economic development potential and constraints to local foods development in the Midwest. Paper presented at the annual meeting of the Southern Regional Science Association, Washington, D.C. Available at the Iowa State University Department of Economics website: http://www.econ.iastate.edu/research/ other/p12697

Thilmany, D., Gunter, A., \& Sullins, M. (2011, July). Farm to school: Tools to assess and evaluate impacts on producers and regions. Paper presented at the CENET Track Session, Economic Contributions from a More Localized Food System, annual meetings of the American Agricultural and Applied Economics Association, Pittsburgh, Pennsylvania.

Thilmany, D., McKenney, N., Mushinski, D., \& Weiler, S. (2005). Beggar-thy-neighbor economic development: A note on the effect of geographic interdependencies in rural retail markets. The Annals of Regional Science, 39(3), 593-605. http://dx.doi.org/10.1007/s00168-005-0229-x

Zezima, K. (2011, August 20). As farmers' markets go mainstream, some fear a glut. New York Times, p. A12. 